\title{
Contribuição Teórica Austro-Libertária das Relações Internacionais
}

\author{
Nathan Cardoso Farinha ${ }^{I}$ (D) 0000-0003-2971-2899 \\ Universidade Federal de Goiás - Goiânia - Goiás - Brasil
}

Resumo: O artigo sintetiza e analisa os aportes teóricos dos autores austro-libertários em temas da área de Relações Internacionais. Com uma percepção crítica sobre o comportamento do Estado como agente fundamental na problemática global, o artigo discute a possibilidade de um aporte da teoria austro-libertária a essa área de estudo.

Palavras-chave: Relações Internacionais, teoria das Relações Internacionais, austro-libertário, libertarianismo.

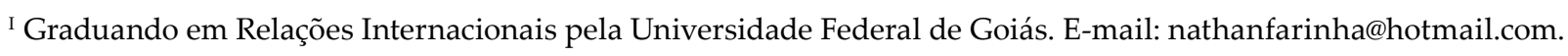




\title{
Theoretical Austro-Libertarian Contribution to International Relations
}

\begin{abstract}
The article synthesizes and analyzes the theoretical contributions of Austro-libertarian authors in themes in the field of International Relations. With a critical perception around the behavior of the State as a fundamental actor in global issues, this paper discusses the possibility of a contribution by Austro-libertarian theory to this area of study.
\end{abstract}

Keywords: International relations, international relations theory, austro-libertarianism, libertarianism.

\section{Contribución Teórica Austrolibertaria a las Relaciones Internacionales}

Resumen: El artículo sintetiza y analiza los aportes teóricos de autores austrolibertarios en temas del campo de estudio de las Relaciones Internacionales. Con una percepción crítica en torno al comportamiento del Estado como actor fundamental en la problemática global, el artículo discute la posibilidad de un aporte de la teoría austrolibertaria a esta área de estudio.

Palavras clave: Relaciones internacionales, teoría de las relaciones internacionales, austro-libertario, libertarianismo. 


\section{Introdução}

As Relações Internacionais, como disciplina, surgem no contexto do intervalo entre as duas guerras mundiais, visando a investigação das dinâmicas que envolviam a interação entre as nações e o entendimento de quais seriam os fatores motivadores dos conflitos mundiais e, se possível, como evitá-los (CARR, 2001). Nos Estados Unidos, a disciplina emerge como um novo pilar da ciência política, ao passo que na academia britânica assume características mais interdisciplinares, abrangendo análises econômicas, históricas e de outras ciências sociais.

As Relações Internacionais se contextualizam por bastante tempo, desde sua origem, pela predominância das teorias do mainstream ${ }^{1}$, mais especificamente, o Realismo, o Liberalismo, e suas posteriores vertentes. Com o passar do tempo, teorias críticas e contestadoras, como o marxismo, a teoria crítica e a pós-estruturalista, surgiram como contribuição ao estudo e ao pensamento da disciplina.

Embora o Libertarianismo não seja propriamente classificado como uma teoria das Relações Internacionais, os autores austrolibertários discorreram inúmeras vezes sobre diversos tópicos que envolvem esse campo de estudo, como as motivações de conflitos entre as nações e a atuação dos Estados no sistema internacional. O presente artigo busca analisar essa concepção crítica e cética em torno dos Estados - oferecida pelo Libertarianismo - e sua possível contribuição para o estudo das Relações Internacionais.

A questão proposta nessa pesquisa é, portanto: qual a contribuição do Libertarianismo para os diferentes tópicos do campo de estudo das Relações Internacionais? Pretende-se respondêla através da seguinte estrutura: a) uma apresentação introdutória do pensamento libertário; b) em seguida, uma investigação das perspectivas dos autores libertários sobre determinados tópicos das Relações Internacionais: I) as características dos Estados; II) o comportamento dos Estados no sistema internacional; III) a tradução desse comportamento nas políticas externas e nas dinâmicas internacionais modernas; c) Por fim, o intuito é formular as possibilidades de contribuições teóricas libertárias ao estudo das Relações Internacionais, frente ao panorama construído por outras teorias.

A metodologia usada é a de pesquisa bibliográfica, de modo a analisar e produzir uma revisão de literatura de obras libertárias que contemplem as temáticas teóricas das Relações Internacionais.

\footnotetext{
${ }^{1} \mathrm{O}$ mainstream das Relações Internacionais é atribuído ao Realismo e ao Liberalismo pois essas teorias dominam as principais discussões acadêmicas desde sua origem como disciplina. Ambas protagonizaram o primeiro grande debate da disciplina, denominado "Realismo vs. Idealismo", onde a parte realista defendeu a configuração do sistema internacional como extremamente favorável ao conflito, ao passo que os idealistas visualizavam a possibilidade de paz por via das instituições. Mais tarde, no terceiro grande debate da disciplina, o chamado "neo-neo", mais uma vez questões paradigmáticas da disciplina, dessa vez a cerca da capacidade da interpendência complexa inviabilizar os conflitos internacionais, Realismo e Liberalismo mantiveram seu protagonismo. Subdisciplinas ou disciplinas-irmãs das Relações Internacionais, como a Análise de Política Externa, também são caracterizadas pelo domínio do pensamento de autores realistas ou liberais no meio acadêmico.
} 


\section{O Pensamento Libertário}

É importante, primeiramente, determinar a vertente teórica do Libertarianismo (eventualmente apresentado como libertarismo) a que esse artigo se refere, tendo em vista o uso histórico do termo por diferentes concepções teóricas do espectro político, desde a esquerda até a direita. Aqui, propõe-se a discussão do Libertarianismo proprietário ou individual, movimento com elementos do liberalismo clássico e do direito natural, tendo seu contexto de origem no século XX.

Para o libertarismo, os indivíduos (e não os grupos) são primários, tanto do ponto de vista normativo como ontológico. Por conseguinte, a filosofia libertária vê o indivíduo como moralmente soberano e como a base de qualquer construção social. A filosofia em questão considera também que os indivíduos têm direitos que os protegem da interferência coerciva de outros. Na percepção libertária, só ações voluntárias são moralmente legítimas. O libertário entende a liberdade económica e os direitos de propriedade como sendo de extrema importância para uma sociedade justa. Neste sentido, o libertarismo assemelha-se a uma doutrina rigorosa de capitalismo laissez-faire (FARIA, 2019).

No presente artigo, optou-se por discutir, no entanto, a vertente austrolibertária, influenciada pelo pensamento construído pela Escola Austríaca de Economia, tendo entre seus principais autores, Murray Rothbard, Ludwig von Mises, Friedrich Hayek e Hans-Hermann Hoppe. O austrolibertarianismo, enfatiza a propriedade privada como elemento fundamental na defesa da liberdade individual, e de modo algum ela deve ser violada por qualquer agressor, exceto em casos de legítima defesa.

Os teóricos austrolibertários apontam o Estado, que surge como resultado de um processo de coerção "como o supremo, eterno e mais bem organizado agressor das pessoas e da propriedade de grande parte do público" (ROTHBARD, 2013, p. 64). No campo econômico, os austrolibertários questionam a interferência dos governos nos mercados, provocando distorções, má alocação de recursos e desvalorização das moedas.

\section{Perspectivas e Discussões Sobre as Relações Internacionais nas Obras Austrolibertária}

\subsection{A teoria das Relações Internacionais}

A teoria Realista foi, por muito tempo, hegemônica no estudo das Relações Internacionais. Sua premissa principal é a de que os Estados são os atores determinantes no sistema internacional. Os Estados são atores unitários, que agem de maneira uniforme em um contexto anárquico (o sistema internacional não possui uma liderança capaz de coercitivamente aplicar um conjunto normativo ou controlar seu funcionamento), e dessa forma, o principal objetivo dos tomadores de decisões é a sobrevivência. A racionalidade e o "interesse próprio" dos Estados, que devem agir com constante desconfiança em um ambiente competitivo, são reflexos de uma percepção negativa da natureza humana pelos realistas. 
Morgenthau (1948) destaca que as ações políticas determinantes são baseadas não em acordo com normas morais, mas sim, na busca constante pelo poder. As críticas constantes à teoria e sua capacidade de explicar os eventos mais recentes da política internacional, no entanto, levaram ao surgimento de diversas outras vertentes realistas. O neorrealismo de Kenneth Waltz dá a teoria um embasamento no método científico, afirmando que o comportamento dos atores no sistema internacional é determinado por fatores estruturais, como a percepção dos níveis diferentes de poderes disponíveis a cada Estado e a essência anárquica do sistema internacional (WALTZ, 1978), se distanciando assim das concepções essencialistas da natureza humana.

As críticas à teoria realista se intensificaram de forma mais incisiva com o término da Guerra Fria, onde o fim de uma estrutura de poder bipolar não levou o sistema internacional a uma situação de mais instabilidade e conflito (como previam os teóricos realistas), mas sim, à uma organização mais propensa a estabilidade, a paz e a cooperação.

A teoria liberal é a segunda grande protagonista nas discussões teóricas das Relações Internacionais. Com uma perspectiva mais positiva da natureza humana e mais otimista em relação ao progresso, o liberalismo enfatiza que, apesar da estrutura anárquica do sistema internacional, arranjos de paz e cooperação são possíveis, à medida em que se reúnam interesses comuns dos atores internacionais que, na visão liberal, não se limitam somente aos Estados, mas também as instituições, organizações transnacionais e as personalidades políticas.

Em um aspecto normativo, a teoria liberal enfatiza o dever prioritário dos Estados de proteger o bem estar e a liberdade de sua população. Tais atitudes, inclusive, quando exercidas internamente nos Estados, são capazes de se projetarem em sua atuação também no sistema internacional, dessa forma, quanto mais democráticas, institucionalizadas e protetoras de liberdades forem as nações, menos propensas ao conflito elas estariam entre si.

O institucionalismo, uma das vertentes posteriores do liberalismo, destaca a situação de interdependência complexa em que se configura o sistema internacional moderno, onde o mercado mundial se encontra em uma posição de extrema integração, de forma que conflitos em escala global se tornam inviáveis e improváveis pela capacidade de causar efeitos negativos em todos os países, independentemente do resultado militar.

Em uma aproximação mais recente, a neoliberal, teóricos importantes da disciplina, Nye e Keohane (1987) enfatizam a discussão da chamada interdependência complexa, na qual as relações mundiais, especialmente as econômicas, se tornaram tão sólidas e frequentes, que a cooperação tenderá a se intensificar e a possibilidade de um conflito de altas proporções seria extremamente improvável, ao passo em que as eventuais perdas econômicas seriam consideravelmente distantes dos ganhos obtidos por um eventual vencedor.

Embora essas duas teorias tenham sido as mais predominantes no campo de estudo das Relações Internacionais, há uma diversidade de outras teorias, como a construtivista, marxista, pós estruturalista, dentre outras, que buscam explicar as dinâmicas das relações entre os Estados de forma mais crítica ao mainstream da disciplina. Como expressado anteriormente, o objetivo desse artigo é então a sintetizar as discussões austrolibertárias que tratam de 
dinâmicas inerentes as Relações Internacionais de forma a avaliar uma possível contribuição teórica, majoritariamente crítica, para a disciplina.

\subsection{As Características dos Estados}

Para os libertários, "os Estados surgem, em sociedades, quando pessoas utilizam a força umas contra as outras e quando toda uma estrutura institucional se estabelece a partir dessa relação" (HAMOWY, 2008, p. 490, [tradução nossa]). Dessa forma, sua natureza é coercitiva e não voluntária. Essa posição também determina uma relevante divergência inicial entre a teoria austrolibertária e as teorias estabelecidas das Relações Internacionais: Estados não são arranjos sociais para a garantia da segurança ou a proteção de direitos, mas sim, um instrumento de determinados indivíduos para coerção e exploração.

As discussões austrolibertárias! não necessariamente sobre as relações internacionais, mas sobre as dinâmicas políticas e econômicas, colocam o Estado e sua atuação como o ponto central. Dessa forma, é inevitável constatar que as contribuições desses autores para a discussão das questões internacionais também partem de uma afirmação dos Estados como atores fundamentais no contexto aqui discutido. O Estado, como "organização social que visa manter o monopólio do uso da força e da violência em uma determinada área territorial" (ROTHBARD, 2012, p. 8-9), na visão austrolibertária, busca perpetuar sua condição de coerção e tornar-se cada vez mais forte nesse sentido.

O Estado, a fim de manter essa condição pode agir de diversas maneiras. Dentre elas, a violação de direitos fundamentais, como a espoliação da propriedade (BASTIAT, 2019) e a construção de estruturas burocráticas mantedoras de privilégios (ROTHBARD, 2012). Do ponto de vista ideológico, o Estado é capaz de construir noções comuns, através de ferramentas como educação e propaganda, que sua grande dimensão, ou mesmo existência, é necessária para a proteção de sua população contra ameaças internas e externas.

\subsection{O Comportamento do Estado e seus Objetivos no Sistema Internacional}

Os conflitos e suas motivações sempre estiveram entre os principais questionamentos abordados pelas Relações Internacionais. Tucídides (2001), ao elaborar suas percepções em torno da Guerra do Peloponeso, teria dado uma primeira contribuição realista a esse campo de estudo. Immanuel Kant, em A Paz Perpétua (2008), discorre, de forma idealística e normativa, possíveis caminhos para um estado de paz no sistema internacional. Ao analisarmos a visão austrolibertária, percebe-se a guerra como mais um instrumento (mas um dos mais poderosos entre todos) de uso do Estado para ampliar seu processo coercitivo e da violação das liberdades, como afirma Hoppe (2018), teórico libertário, sobre a lógica por trás da motivação dos administradores do Estado na promoção de conflitos:

Primeiro, os plutocratas perceberão rapidamente os enormes lucros que podem ter armando o Estado, produzindo as armas e os equipamentos usados nas guerras, e ganhando contratos onerosos e superfaturados financiados com impostos para tanto. Um complexo militar será construído. Depois, ao contrário da maioria das pessoas que têm apenas interesses locais ou domésticos, os plutocratas super-ricos têm interesses financeiros no mundo todo, 
e, a fim de promover, proteger e aplicar estes interesses estrangeiros, é natural que usem o podem militar do próprio Estado para interferir, se intrometer ou intervir em assuntos externos em seu nome. (HOPPE, 2018, p. 138-139)

Para Rothbard (2012), é inerente aos Estados o desejo de expansão e conquista de novos territórios. Há aqui uma convergência entre diversos autores para ideia de que durante o contexto de coerção e expropriação interna (nacional), ou os recursos inevitavelmente se esgotam, ou surge uma necessidade dos Estados de balancear sua exploração em direção a outros territórios, para que um cenário de descontentamento extremo de sua população não se estabeleça.

Nesse sentido, não só há um interesse por parte do Estado em se proteger das ameaças internacionais através de sua expansão, como afirma o realismo, mas também em ampliar e intensificar ainda mais a exploração dos indivíduos no seu próprio interior. Mais especificamente o governo central, através das guerras se torna ainda mais forte no cenário interno do ponto de vista de coerção política, ao diminuir ou destituir direitos fundamentais em nome da segurança nacional (HOPPE, 2018). Incremento de gastos militares advindos do aumento de impostos, aumento do déficit, violação de liberdades civis individuais, aumento do poder do governo federal e maior instabilidade constitucional são exemplos de consequências internas em função da expansão externa de um país (HAMOWY, 2008).

Em outro pilar das Relações Internacionais, mais especificamente a economia política internacional, Hayek (2010) aponta ainda o papel desastroso que a planificação econômica pode ter na geração de atritos internacionais. Uma planificação econômica internacional é impraticável senão pela restrição da livre movimentação de pessoas e produtos e pela coerção, "por parte de um reduzido grupo, do tipo de trabalho e do padrão de vida que os planejadores julgam convir aos demais" (HAYEK, 2010, p. 208).

É de extrema importância ainda ressaltar que, ao se envolverem em conflitos, os Estados buscam, de forma a reforçar seu poder, uma centralização, que, no contexto das dinâmicas globais, se materializa nas instituições internacionais. Por meio de organizações militares e de segurança, os Estados se utilizam da possibilidade de se construir uma eventual legitimidade na interferência externa, por trás de uma promessa de paz e estabilidade. Dessa forma, constroem instrumentos imperialistas, em que os mais poderosos se sobrepõem aos mais fracos com interesses que só podem ser atingidos através da violação das liberdades fundamentais.

Em adição, por meio das instituições econômicas, os Estados fortalecem sua hegemonia, definindo as regulamentações do sistema monetário internacional e perturbando a integração econômica entre as nações:

A integração política (centralização) e a integração econômica (mercado) são dois fenômenos completamente diferentes. A integração política envolve a expansão territorial do poder de tributação e de regulação das propriedades (expropriação) de um estado. A integração econômica é a ampliação da divisão do trabalho e a da participação no mercado em âmbito interpessoal e inter-regional. (HOPPE, 2014, p. 143) 
Como as teorias de Relações Internacionais tradicionalmente afirmam, é inevitável que a atuação do Estado internamente se projete em uma atuação semelhante no sistema internacional. É possível aqui sustentar, que também na perspectiva austrolibertária, a atuação externa dos Estados se confunde com sua atuação interna à medida em que estes buscam, da mesma maneira no sistema internacional, a expansão da exploração de recursos, da coerção e das restrições econômicas e liberdades individuais que ameassem sua condição de autoridade.

\subsection{Tradução do Comportamento nas Políticas Externas e nas Dinâmicas Internacionais Modernas}

\subsubsection{O imperialismo e a hegemonia americana}

A maior parte das discussões austrolibertárias trazem a política externa americana como exemplo teórico da projeção do Estado no ambiente político mundial. Os Estados Unidos, que no princípio adotavam uma postura isolacionista no sistema internacional, viram o envolvimento nas constantes guerras como uma oportunidade de dominação desse contexto, se tornando hegêmona e impondo instrumentos imperialistas por todo o mundo, como sua moeda na posição de reserva internacional (HOPPE, 2018). A Guerra ao Terror, após os atentados de 11 de setembro, se mostrou não só desastrosa do ponto de vista externo, como também foi nociva a garantia de inúmeras liberdades individuais de cidadãos americanos (HAMOWY, 2008). Em notáveis outras intervenções americanas na conjuntura política de outros países, principalmente no Oriente Médio, em busca de firmar sua liderança em uma ordem liberal democrática, os Estados Unidos provocaram ainda mais movimentos antiocidentais.

\subsubsection{Discurso democrático}

O discurso democrático se dá, no sistema internacional, como eventual potencializador dos conflitos. Hoppe (2018), afirma que a democracia aumenta a identificação do povo com o Estado e torna a guerra universal. Rothbard (2012) destaca que previamente aos séculos mais recentes, era clara a separação entre a sociedade civil e as guerras do Estado. Contrariando a tese institucionalista de que democracias não são propensas a guerras entre si, Radnitzky (2003) afirma que os Estados que buscam causar um conflito sempre chamarão o adversário de antidemocrático, e que para uma guerra aconteça, medidas não democráticas terão que ser tomadas pelo próprio Estado que inicia a guerra. Os conflitos mundiais do século XX trouxeram a população civil para a condição de alvo e os líderes direcionaram a opinião pública para a guerra, por meio de um controle midiático.

\subsubsection{Globalização e desenvolvimento econômico}

A globalização é vista, pelos libertários, como uma oportunidade para o intercâmbio de culturas, que gerem conexões comerciais e de liberdades. Ela é capaz de integrar culturas e mercados, promovendo um desenvolvimento não só econômico, de grande benefício para as nações mais pobres - ao atrair investimentos, tecnologia, novos produtos e oportunidades 
profissionais para sua população - como também de promover um referencial comum de valores quanto aos direitos fundamentais para a sociedade mundial.

Para Hoppe (2014), a imigração livre tem o poder de aumentar rendimentos reais para trabalhadores domésticos e conter a fuga de capitais, ao passo que o protecionismo internacional é o caminho para problemas econômicos em todas as nações. Tais fatores, enfatizam a posição libertária de que a desigual distribuição econômica entre os países mundiais não é motivada pela exploração dos países periféricos, ou terceiro mundo, pelos países centrais, como apontam determinadas teorias críticas das Relações Internacionais, mas sim pela violação da liberdade econômica (HAMOWY, 2008) e da livre imigração.

\subsubsection{Pequenas nações e movimentos em direção à separação}

Como parte relevante da agenda internacional do século XX e XXI estão presentes as situações de diversas comunidades que, de alguma forma, se inquietaram diante de movimentos autoritários ou imperialistas em diversas ordens, que reprimem sua autonomia e poder de decisão. A expansão do Estado, em algum momento, torna sua política interna insustentável, pela diminuição da produtividade e a incapacidade da manutenção de políticas assistencialistas, o que leva a crises e o desejo de separação em estados menores (HOPPE, 2018). Movimentos separatórios, exemplificados por diversas comunidades como Kosovo e Catalunha, revoltas políticas como Hong Kong e Taiwan, ou mesmo o desligamento de instituições supranacionais, como o Brexit, são exemplos de estresses em relações de expansão externa dos Estados.

\section{Possibilidades de Contribuição Libertária para o Campo Teórico das Relações Internacionais}

O campo teórico das Relações Internacionais é marcado pela predominância das teorias mainstream, com um espaço pouco considerável para teorias críticas e revisoras. A teoria austrolibertária, embora não seja, em sua origem, uma teoria das Relações Internacionais, contém, como explorado nesse artigo, contribuições em diversas temáticas presentes no campo de estudo da disciplina.

Ainda relativamente inexplorada pela disciplina, a teoria austrolibertária é capaz de oferecer uma inovadora e contestadora concepção do comportamento do principal ator no sistema internacional: o Estado. No panorama das outras teorias críticas mais exploradas pelo campo de estudo, como o Marxismo, o sistema econômico capitalista é responsabilizado pelos conflitos, divergências e a exploração entre determinadas nações no contexto global. A teoria austrolibertária, por sua vez, é capaz de oferecer uma abordagem díspar. Os Estados, ao deterem o monopólio da violência e utilizarem deste para impor seu sistema legal, bem como acentuar a exploração de recursos por meio da coerção, são causadores das principais problemáticas hoje presentes no sistema internacional.

A guerra, é um dos principais e necessários instrumentos dos Estados para ampliar sua condição de dominação e exploração. Por meio do discurso democrático, os Estados envolveram nos conflitos recentes a população civil como nunca antes havia feito nos séculos anteriores. $\mathrm{O}$ 
imperialismo americano, em nome de uma ordem democrática liberal, foi precursor de mais violações nas liberdades individuais e do crescimento de sentimentos antiocidentais terroristas. O Estado, ao restringir a livre circulação de pessoas entre as nações e proliferar instrumentos regulatórios no sistema de comércio mundial é ainda o principal inimigo do desenvolvimento econômico global, principalmente dos países hoje considerados menos desenvolvidos.

Dito isso, é impertinente negar que a teoria austrolibertária oferece contribuições teóricas em grande parte das principais temáticas discutidas pelos acadêmicos da disciplina de Relações Internacionais, questionando ao mesmo momento, as definições das teorias do mainstream da disciplina e as afirmações críticas até então apresentadas.

A teoria austrolibertária também é capaz de oferecer uma posição importante frente à temas presentes frequentemente na disciplina. Austrolibertários afirmam que o livre comércio, entre as nações e o livre trânsito entre pessoas de nacionalidades diferentes, é o melhor caminho para atingir um estado de paz no sistema internacional (MISES, 2010). Ainda, os conflitos contemporâneos entre os Estados são incapazes de possuir legitimidade, à medida em que envolvem indivíduos externos, como a população civil e se justificam por motivações muito além do direito de defesa:

A atitude básica do libertário em relação à guerra deve ser: É legítimo usar a violência contra criminosos em defesa de seus direitos pessoais e de propriedade; é totalmente inadmissível violar os direitos de outras pessoas inocentes. A guerra, então, só é apropriada quando o exercício da violência é rigorosamente limitado aos criminosos individuais. Podemos julgar por nós mesmos quantas guerras ou conflitos na história atenderam a este critério. (ROTHBARD, 2003, p. 68, [tradução nossa])

\section{Conclusão}

Como discutido, o componente teórico do pensamento austrolibertário, em torno das Relações Internacionais, faz referência ao Estado de forma crítica, posicionando-o como ator principal e motivador das principais problemáticas globais contemporâneas. Essa perspectiva é importante para a construção de uma teoria crítica capaz de questionar as afirmações em torno da disciplina, sustentadas pelas teorias mainstream, e ao mesmo tempo, questionar a atribuição das disfunções globais ao sistema capitalista, advindas das já estabelecidas teorias críticas no estudo das Relações Internacionais.

Este artigo apontou que uma interpretação austrolibertária das relações internacionais é construída principalmente pela: 1) crítica à legitimidade e ao comportamento dos Estados no sistema internacional e 2) o uso da guerra, das ferramentas regulatórios e da formação de instituições globais como instrumentos para o aumento da exploração e dominação dos Estados.

Mostrou-se que, além de uma contribuição crítica não só ao campo teórico dominante da disciplina, como também às afirmações de outras teorias críticas das Relações Internacionais, a visão austrolibertária é capaz de oferecer aspectos contestadores da agenda política mundial contemporânea, ao contestar a possibilidade de uma planificação econômica mundial, e ao 
defender o livre comércio e a livre circulação de pessoas, como elementos fundamentais para o desenvolvimento.

\section{Referências}

CARR, E. H. Vinte Anos de Crise: 1919-1939. Brasília: UNB, 2001.

FARIA, F. N. Libertarismo. In: MARQUES, António; CAMPOS, André (coords). Dicionário de Filosofia Moral e Política. Lisboa: Instituto de Filosofia da Nova, 2019. Disponível em: http://www.dicionariofmp-ifilnova.pt/ libertarismo. Acesso em: 11 fev 2021.

HAMOWY, Ronald. The Encyclopedia of Libertarianism. [S. l.]: Sage Publications, 2008.

HAYEK, F. A. O caminho da servidão. São Paulo: Instituto Ludwig von Mises Brasil, 2010.

HOPPE, Hans-Hermann. Democracia, o Deus que falhou. 1. ed. São Paulo: Instituto Ludwig von Mises Brasil, 2014.

HOPPE, Hans-Hermann. Uma Breve História do Homem: Progresso e Declínio. São Paulo: LVM, 2018.

KANT, Immanuel. A paz perpétua: Um projeto filosófico. Covilhã: LusoSofia press, 2008.

KEOHANE, Robert O.; NYE, Joseph S. Power and Interdependence revisited. International Organization, [s. l.], v. 41, ed. 4, p. 725-753, 1987.

MISES, Ludwig von. Omnipotent Government: The rise of the total state and total war. [S. l.]: Mises Institute, 2010.

RADNITZKY, Gerard. Is democracy more peaceful than other forms of government? In: HOPPE, HansHermann. The Myth Of National Defense. Auburn: Ludwig von Mises Institute, 2003.

ROTHBARD, Murray N. War, Peace and the State. In: HOPPE, Hans-Hermann. The Myth Of National Defense. [S. l.]: Ludwig von Mises Institute, 2003.

ROTHBARD, Murray N. A anatomia do estado. São Paulo: Instituto Ludwig von Mises Brasil, 2012.

ROTHBARD, Murray N. Por uma Nova Liberdade: O Manifesto Libertário. 1. ed. São Paulo: Instituto Ludwig von Mises Brasil, 2013.

TUCÍDIDES. História da Guerra do Peloponeso. Brasília: Universidade de Brasília, 2001.

RECEBIDO EM: 20 DE FEVEREIRO DE 2021. APROVADO EM: 08 DE MARÇO DE 2021. 